\title{
IIII Physician Counseling on Colorectal Cancer Screening and Receipt of Screening among Latino Patients
}

\author{
Anna M. Nápoles, $P h D^{1,3}$, Jasmine Santoyo-Olsson, MS ${ }^{1,2}$, Anita L. Stewart, PhD², \\ Jill Olmstead, MSN, ANP-BC ${ }^{5}$, Steven E. Gregorich, $P h D^{7}$, Georgianna Farren, MD, MEd ${ }^{4}$, \\ Ruben Cabral, $\mathrm{MD}^{6}$, Andrew Freudman, $\mathrm{MPHC}^{7}$, and Eliseo J. Pérez-Stable, $\mathrm{MD}^{1,3}$
}

\begin{abstract}
'Division of General Internal Medicine, Department of Medicine, and Medical Effectiveness Research Center for Diverse Populations, University of California San Francisco (UCSF), San Francisco, CA, USA; ${ }^{2}$ Institute for Health \& Aging, UCSF, San Francisco, CA, USA; ${ }^{3} \mathrm{Helen}$ Diller Family Comprehensive Cancer Center, UCSF, San Francisco, CA, USA; ${ }^{4}$ Marin Community Clinics, San Rafael, CA, USA; ${ }^{5}$ St. Jude Heritage Health Foundation, Fullerton, CA, USA; ${ }^{6}$ St. Jude Heritage Medical Group, Fullerton, CA, USA; ${ }^{7}$ Department of Global Health, University of Seattle, Washington, Seattle, WA, USA.
\end{abstract}

BACKGROUND: Latinos have lower rates of colorectal cancer (CRC) screening and later stage diagnosis than Whites, which may be partially explained by physician communication factors.

OBJECTIVE: We assessed associations between patientreported physician counseling regarding CRC screening and receipt of CRC screening among Latino primary care patients.

DESIGN: This was a cross-sectional telephone survey.

PARTICIPANTS: The participants of this study were Latino primary care patients 50 years of age or older, with one or more visits during the preceding year.

MAIN MEASURES: We developed patient-reported measures to assess whether physicians provided explanations of CRC risks and tests, elicited patients' barriers to CRC screening, were responsive to patients' concerns about screening, and encouraged patients to be screened. Outcomes were patient reports of receipt of endoscopy (sigmoidoscopy or colonoscopy) and fecal occult blood test (FOBT) within recommended guidelines.

KEY RESULTS: Of 817 eligible patients contacted, 505 (62\%) completed the survey; mean age was 61 years (SD 8.4), $69 \%$ were women, and $53 \%$ had less than high school education. Forty-six percent reported obtaining endoscopy (with or without FOBT), $13 \%$ reported FOBT only, and $41 \%$ reported no CRC screening. In bivariate analyses, physician explanations, elicitation of barriers, responsiveness to concerns, and greater encouragement for screening were associated with receipt of endoscopy $(p<$ $0.001)$, and explanations $(p<0.05)$ and encouragement $(p<$ 0.001 ) were associated with FOBT. Adjusting for covariates, physician explanations (OR=1.27; $95 \%$ CI 1.03, 1.58) and greater physician encouragement (OR=6.74; $95 \%$ CI 3.57, 12.72) were associated with endoscopy; patients reporting quite a bit/a lot of physician encouragement had six times higher odds of obtaining the FOBT as those reporting none/a little encouragement $(\mathrm{OR}=6.54$; $95 \%$ CI 2.76, 15.48).

Electronic supplementary material The online version of this article (doi:10.1007/s11606-014-3126-0) contains supplementary material, which is available to authorized users.

Received May 26, 2014

Revised November 5, 2014

Accepted November 17, 2014

Published online December 4, 2014
CONCLUSIONS: Among primarily lower-socioeconomic status Latino patients, the degree to which patients perceived that physicians encouraged CRC screening was more strongly associated with screening than with providing risk information, eliciting barriers, and responding to their concerns about screening.

KEY WORDS: colorectal cancer screening; physician-patient communication; Latinos; Hispanic; quality of care.

J Gen Intern Med 30(4):483-9

DOI: $10.1007 / \mathrm{s} 11606-014-3126-0$

(c) Society of General Internal Medicine 2014

\section{INTRODUCTION}

Colorectal cancer (CRC) is the second leading cause of cancer-related death in Latino men and the third leading cause in Latino women. ${ }^{1}$ Latinos are more likely than non-Latino Whites to be diagnosed with advanced CRC and experience lower five-year survival rates. Mexicans, South/Central Americans, and Puerto Ricans were 10-60 \% more likely than nonLatino Whites to be diagnosed with Stage III or IV CRC, ${ }^{2}$ as is true for Latinos overall. ${ }^{1,3}$ These disparities are attributable in part to lower rates of CRC screening among Latinos than Whites. In 2010, $47 \%$ of Latinos versus $62 \%$ of Whites in the U.S. obtained any type of CRC screening. ${ }^{1}$

Prior studies have identified several barriers to CRC screening among Latinos. Primary among them are limited access to care and lack of health insurance. ${ }^{1}$ Attitudinal factors associated with inadequate CRC screening among Latinos include believing they do not need screening due to no symptoms, fatalism, fears of pain associated with CRC screening, lack of perceived susceptibility to CRC, and embarrassment. ${ }^{4-9}$ Limited CRC screening knowledge among Latinos is another factor; ${ }^{6,7}$ a national survey found that of all ethnic groups, knowledge of CRC screening was poorest among Latinos, with only $48 \%$ being familiar with the term "colonoscopy," compared to $85 \%$ of the total sample. ${ }^{10}$ Limited English proficiency (LEP) and language discordance between Spanish-speaking patients and their physicians also contribute to lower rates of CRC screening among Latinos. ${ }^{11,12}$ LEP 
Mexican Americans were twice as likely as non-LEP Mexican Americans and Whites to indicate they did not obtain endoscopic CRC screening because their clinician did not recommend it or did not strongly emphasize its importance. ${ }^{11}$

Many barriers to CRC screening can be addressed through focused physician-patient communication. Clinician communication behaviors such as providing explanations about screening tests and their benefits, addressing potential patient barriers to screening, and responding to patients' concerns, might enhance patients' motivation to obtain screening.

The purpose of this paper is to examine whether specific clinician counseling behaviors pertaining to CRC screening are associated with receipt of CRC screening among underserved Latino men and women age 50 and older. Specifically, we sought to examine whether explanations of CRC risk and screening tests, elicitation of patients' barriers to screening, responsiveness to patients' CRC screening concerns, and encouragement of CRC screening by primary care physicians were associated with adequate CRC screening. Given timeconstrained primary care visits, identification of specific physician CRC counseling components that are more strongly associated with screening might facilitate more focused discussions with a higher likelihood of CRC screening compliance.

\section{METHODS}

\section{Setting and Sample}

Our sample consisted of adult general medicine patients from a large Southern California multi-specialty practice and three community clinics, one in Southern California and two in Northern California. The community clinics were safety net clinics serving mostly uninsured or under-insured, lowincome patients. The proportion of Latino patients seen at the community clinics ranged from 56 to $80 \%$, while the multi-specialty group practice served a more socioeconomically and ethnically diverse patient population.

The sampling frame consisted of 1,314 adults who met inclusion criteria of: 1) at least one primary care provider (PCP) visit between 1 January 2007 and 2 September 2008 to participating sites of care; 2) $\geq 50$ years of age, 3) Latino (confirmed by self-identification), 4) English-speaking or Spanish-speaking, and 5) no personal history of CRC. Stratifying by clinic site, we randomly selected individuals from the sampling frame, aiming for 500 interviews with equal representation from each site. Patients' PCPs were given a list of their patients meeting inclusion criteria and asked to opt out any who should not be contacted.

\section{Procedures}

A bilingual low-literacy letter, information sheet and refusal postcard were mailed to patients. Patients who did not return the refusal postcard were contacted by telephone two weeks later by experienced bilingual-bicultural interviewers. Telephone interviews were conducted in English or Spanish (per respondent's preference) between October 2008 and May 2009 using computerized telephone-assisted survey methods, and lasted about 30 minutes. Interviewers and respondents were gender-matched for most interviews. Interviewers obtained verbal consent and participants were paid \$25. Procedures were approved by the academic health center's institutional review board.

\section{Measures}

Colorectal Cancer Screening Counseling. Based on the literature and the Interpersonal Processes of Care Survey, ${ }^{13}$ we developed a new Colorectal Cancer Screening Counseling Survey that assesses counseling behaviors pertaining to CRC screening. Items were translated into Spanish using rigorous translation methods (i.e., forward-backward translations by bilingual bicultural research staff and team reconciliation) and cognitively pretested among 15 Latinos (three in English; 12 in Spanish). Multi-trait scaling analysis methods were employed to confirm the hypothesized scales. ${ }^{14}$

The 13-item CRC-Counseling Survey contains three multiitem scales plus a single item. The scales are: explanations of $C R C$ risks/tests (five items; Cronbach's alpha $=0.85$ ); elicitation of patient's CRC screening barriers (five items; alpha $=0.80$ ); and responsiveness to patient's CRC screening concerns (two items; alpha $=0.85$ ). All items use a yes/no response option as to whether physicians had ever performed the counseling behavior; scores are the count of items with a "yes" response. A single item assesses patients' perceived level of encouragement by their physician to get screened (dichotomized as quite a bit/a lot vs. none/a little). Survey items are shown in the online Appendix.

Colorectal Cancer Screening Adherence. Adherence to fecal occult blood testing (FOBT), sigmoidoscopy, and colonoscopy was self-reported. Following a brief description of the test, participants were asked if they had ever had a FOBT, and if so when: within the past 6 months, 6 months to 1 year ago, between 1 and 2 years ago, between 2 and 5 years ago, or more than 5 years ago. Then, following a brief description of each test, participants were asked if they had ever had a sigmoidoscopy or colonoscopy, and if so when: within the last year, more than 1 year but less than 5 years ago, more than 5 years ago, but less than 10 years ago, or more than 10 years ago. We defined current CRC screening adherence based on the American Cancer Society's Guidelines for the Early Detection of Cancer for average-risk populations ages 50 and older. ${ }^{15}$ Participants were considered adherent for endoscopy screening if they had undergone sigmoidoscopy within the past 5 years or colonoscopy within the past 10 years. Participants were deemed adherent for FOBT if they reported it occurring within the past year. Adherence to any CRC 
testing was defined as adherence to endoscopy or FOBT screening. To analyze independent correlates of FOBT and endoscopy screening, we classified participants into three categories: 1) neither type of screening, 2) endoscopy only or in combination with FOBT, and 3) FOBT only.

Sociodemographic Characteristics and Covariates. Sociodemographic factors included age in years, gender, marital status (married or living with partner vs. not), education in years (less than high school, completed high school, or some college or more), employment status, U.S.born or foreign-born, self-rated health (poor, fair, good, very good, excellent), health insurance status (any private insurance, public insurance only, or no insurance), number of medical visits in the past 12 months, clinic site (Southern California multi-specialty clinic, Southern California community clinic, or Northern California community clinic), language of interview, language concordance of health care provider with participant (non-LEP participant, LEP participant with Spanish-speaking clinician, LEP participant with non-Spanish-speaking clinician), and presence of any CRC risk factors (personal history of colon polyps, personal history of chronic inflammatory bowel disease, first degree relative with CRC before age 60). Participants were deemed LEP if they rated their Englishspeaking ability as "not at all," "poor," or "fair."

\section{Data Analysis}

Chi-square and t-tests were used to assess differences in receipt of screening (versus no test) by sample characteristics. We conducted simple logistic regression analyses to assess bivariate associations between each variable and the three outcomes: adherence to FOBT, adherence to endoscopy (with or without FOBT), and adherence to any CRC testing. Multivariable logistic regression was used to model the independent effects of counseling while controlling for covariates that were significant at the $p \leq 0.25$ level in bivariate analyses of each screening outcome. We used a more liberal cutoff than 0.05 , so as not to rule out variables that might be associated with patient screening behaviors. Statistical significance for multivariable models was established at $p<0.05$. SAS version 9.2 was used for analyses.

\section{RESULTS}

\section{Sample Characteristics}

A total of 1,314 people were mailed an invitation letter. Of the 817 patients who were contacted and eligible, 505 (62\%) completed the survey. Compared to non-respondents, respondents were more likely to be women $(p<0.01)$ and uninsured $(\mathrm{p}<0.01)$.

The mean age of the sample of 505 patients was 61 years (range $=50$ to 91 ), almost $70 \%$ were women, and over half were married (Table 1). The sample tended to be Spanishspeaking immigrants of low socioeconomic status; more than half had less than a high school education, $77 \%$ were foreignborn, almost $70 \%$ had public or no health insurance and $69 \%$ responded in Spanish. About half reported poor or fair health. Respondents had a mean of $6.4(\mathrm{SD}=8.6)$ medical visits in the past 12 months. Of the 354 (71\%) LEP respondents, only 99 $(28 \%)$ saw a clinician who spoke Spanish.

\section{Adherence to CRC Screening}

Overall, $59 \%(\mathrm{~N}=299)$ received CRC screening (either FOBT or endoscopy) within recommended guidelines (Table 2). Of the total sample, $46 \%(\mathrm{~N}=233)$ reported receiving endoscopy (with or without FOBT) and $13 \%(\mathrm{~N}=66)$ reported receiving only FOBT.

\section{Correlates of CRC Screening}

In bivariate analyses (Table 1$)$, being married $(p<0.01)$, having more education $(p<0.001)$, being U.S.-born $(p<$ $0.001)$, having private health insurance $(p<0.001)$, having more annual medical visits $(p<0.05)$, being seen in a multispecialty medical clinic (vs. a community clinic; $p<0.001$ ), doing the interview in English $(p<0.001)$, being fluent in English $(p<0.001)$, and having CRC risk factors $(p<0.001)$ were positively associated with reporting endoscopy within recommended guidelines. For endoscopy, there were no significant differences between those who were screened vs. those who were not screened on age, gender, employment status, or self-rated health. Results for any screening were similar to those for endoscopy. There were no significant differences between participants who reported FOBT in the past year and those who had not received any screening, except for clinic site.

In bivariate analyses (Table 2), all four of the CRC communication factors were significantly related to endoscopy and any screening: explanations of CRC risks/tests, $p<0.001$; elicitation of patient's CRC screening barriers, $p<0.001$; responsiveness to patient's CRC screening concerns, $p<$ 0.001 ; and receiving more encouragement from physicians to get CRC screening, $p<0.001)$. The counseling factors that differed by FOBT screening status were explanations of $C R C$ risks/tests (mean score $=1.1$ for screened vs. 0.7 for unscreened, $p<0.05$ ) and physician encouragement for CRC screening ( $43 \%$ of those screened reported receiving a lot/ quite a bit of encouragement vs. $13 \%$ of those not screened, $p$ $<0.001$ ).

In multivariate analyses (Table 3), for endoscopy, patients from the Southern California $(\mathrm{OR}=0.34 ; 95 \%$ CI $0.12,0.96)$ or Northern California (OR $=0.21 ; 95 \%$ CI $0.08,0.55)$ community clinic were less likely to report endoscopy than multi-specialty clinic patients. Having any known CRC risk factors was associated with more than three times higher odds of having endoscopy, compared to no CRC risk factors. Of the CRC 
Table 1. Respondent Characteristics for Total Sample and by Colorectal Cancer (CRC) Screening Status, in Three California Practice Settings, 2008-2009

\begin{tabular}{|c|c|c|c|c|c|}
\hline Characteristic & $\begin{array}{l}\text { Total } \\
\text { Sample } \\
\text { N=504 }\end{array}$ & $\begin{array}{c}\text { Any CRC } \\
\text { Screening } \\
\mathbf{N}=\mathbf{2 9 9}\end{array}$ & $\begin{array}{c}\text { Endoscopy }^{1} \\
\mathbf{N}=233\end{array}$ & $\begin{array}{l}\text { FOBT }^{1} \\
\text { only } \\
N=66\end{array}$ & $\begin{array}{l}\text { No } \\
\text { Screening } \\
\mathbf{N}=\mathbf{2 0 5}\end{array}$ \\
\hline Age in years: Mean (SD) & $60.6(8.4)$ & $60.9(8.4)$ & $61.1(8.4)$ & $60.3(8.6)$ & $60.1(8.3)$ \\
\hline Sex - women: N (\%) & $350(69)$ & $205(69)$ & $165(71)$ & $40(61)$ & $145(71)$ \\
\hline Marital status - married or living with partner: N (\%) & $266(53)$ & $173(58)^{* *}$ & $138(59)^{* *}$ & $35(54)$ & $93(46)$ \\
\hline Education: N (\%) & & $* *$ & $* * *$ & & \\
\hline Less than high school & $263(53)$ & $143(48)$ & $95(41)$ & $48(74)$ & $120(59)$ \\
\hline High school graduate & $82(17)$ & $46(16)$ & $41(18)$ & $5(8)$ & $36(18)$ \\
\hline Some college or more & $152(31)$ & $106(34)$ & $94(41)$ & $12(18)$ & $46(23)$ \\
\hline Employed full-time or part-time: N (\%) & $219(44)$ & $123(41)$ & $97(42)$ & $26(40)$ & $96(48)$ \\
\hline Born in the U.S.: N (\%) & $116(23)$ & $81(27)^{* *}$ & $73(32)^{* * *}$ & $8(12)$ & $35(17)$ \\
\hline Fair/poor self-rated health: N (\%) & $240(48)$ & $133(44)$ & $101(43)$ & $32(48)$ & $106(52)$ \\
\hline Health insurance: N (\%) & & $* * *$ & $* * *$ & & \\
\hline Any private & $164(33)$ & $118(40)$ & $109(48)$ & $9(14)$ & $46(23)$ \\
\hline Public & $134(27)$ & $73(25)$ & $55(24)$ & $18(28)$ & $61(31)$ \\
\hline Self-pay/no insurance & $193(39)$ & $101(35)$ & $64(28)$ & $37(58)$ & $92(46)$ \\
\hline Number of medical visits in past 12 months: Mean (SD) & $6.4(8.6)$ & $7.1(10.6)^{*}$ & $7.5(11.8)^{*}$ & $5.6(3.8)$ & $5.5(4.1)$ \\
\hline Clinic site: $N(\%)$ & & $* * *$ & $* * *$ & $* * *$ & \\
\hline So. CA multi-specialty clinic & $193(38)$ & $144(48)$ & $133(57)$ & $11(17)$ & $49(24)$ \\
\hline So. CA community clinic & $121(24)$ & $82(27)$ & $54(23)$ & $28(42)$ & 39 (19) \\
\hline No. CA community clinic & $191(38)$ & $73(24)$ & $46(20)$ & $27(41)$ & $117(57)$ \\
\hline Language of interview: N (\%) & & $* * *$ & $* * *$ & $21(41)$ & 111 (נ) \\
\hline English & $157(31)$ & $114(38)$ & $104(45)$ & $10(15)$ & $43(21)$ \\
\hline Spanish & $348(69)$ & $185(62)$ & $129(55)$ & $56(85)$ & $162(79)$ \\
\hline Language concordance: N (\%) & & $* * *$ & $* * *$ & & \\
\hline English proficient & $145(29)$ & $106(36)$ & $96(41)$ & $10(15)$ & $39(19)$ \\
\hline $\begin{array}{l}\text { Limited English proficient with language concordant } \\
\text { physician }\end{array}$ & $99(20)$ & $54(18)$ & $38(16)$ & $16(25)$ & $45(22)$ \\
\hline $\begin{array}{l}\text { Limited English proficient with language discordant } \\
\text { physician }\end{array}$ & $255(51)$ & $137(46)$ & $98(42)$ & $39(60)$ & $118(58)$ \\
\hline CRC risk factors present: $\mathrm{N}(\%)$ & $102(20)$ & $80(27)^{* * *}$ & $76(33)^{* * *}$ & $4(6)$ & $22(11)$ \\
\hline
\end{tabular}

communication factors, a higher mean score on the explanations of CRC risks/tests scale (OR 1.27; $95 \%$ CI $1.03,1.58)$ was associated independently with a higher likelihood of receiving endoscopy; a one-unit increase on the scale was associated with $27 \%$ higher odds of being screened. The amount of encouragement to get screened received from physicians $(\mathrm{OR}=6.74$; $95 \%$ CI $3.57,12.72$ ) was independently associated with a higher likelihood of receiving endoscopic CRC screening, with those who received a lot/quite a bit of encouragement having over six times higher odds of being screened than those reporting none/a little encouragement (adjusted for covariates,
$87 \%$ of respondents reporting quite a bit/a lot of encouragement received any screening versus $51 \%$ of those reporting being encouraged a little or not at all). Results for receiving any CRC screening were similar to those for endoscopic screening.

In multivariate analyses, the only variable that was associated independently with FOBT screening was the amount of encouragement by physicians to get screened $(\mathrm{OR}=6.54 ; 95 \%$ CI 2.76, 15.48); those who received a lot/quite a bit of encouragement had over six times higher odds of being screened than those reporting none/a little encouragement.

Table 2. Physician Counseling Behaviors Reported by Patients by Colorectal Cancer Screening Status, in Three California Practice Settings, 2008-2009 $(\mathrm{N}=\mathbf{5 0 4})$

\begin{tabular}{|c|c|c|c|c|c|}
\hline Characteristic & $\begin{array}{l}\text { Total Sample } \\
\mathbf{N}=\mathbf{5 0 4}\end{array}$ & $\begin{array}{l}\text { Any CRC Screening } \\
\mathrm{N}=\mathbf{2 9 9}\end{array}$ & $\begin{array}{l}\text { Endoscopy }^{1} \\
\mathrm{~N}=\mathbf{2 3 3}\end{array}$ & $\begin{array}{c}\text { FOBT }^{1} \\
\mathrm{~N}=66\end{array}$ & $\begin{array}{l}\text { No Screening } \\
\mathrm{N}=\mathbf{2 0 5}\end{array}$ \\
\hline $\begin{array}{l}\text { Explanations of CRC risks/tests scale }(0-5 \text { scale): } \\
\text { Mean (SD) }\end{array}$ & $1.4(1.7)$ & $2.0(1.8)^{* * *}$ & $2.2(1.8)^{* * *}$ & $1.1(1.6)^{*}$ & $0.7(1.2)$ \\
\hline $\begin{array}{l}\text { Elicitation of patient's CRC screening barriers } \\
\text { scale ( } 0-5 \text { scale): Mean (SD) }\end{array}$ & $0.4(1.0)$ & $0.6(1.2) * * *$ & $0.7(1.3)^{* * *}$ & $0.3(0.8)$ & $0.2(0.5)$ \\
\hline $\begin{array}{l}\text { Responsiveness to patient's CRC screening } \\
\text { concerns scale }(0-2 \text { scale): Mean (SD) }\end{array}$ & $0.3(0.6)$ & $0.4(0.7) * * *$ & $0.5(0.8) * * *$ & $0.2(0.5)$ & $0.1(0.4)$ \\
\hline $\begin{array}{l}\text { Doctor encourages CRC testing: N (\%) } \\
\text { quite a bit or a lot }\end{array}$ & $203(41)$ & $178(61)^{* * *}$ & $150(66)^{* * *}$ & $28(43)^{* * *}$ & $25(13)$ \\
\hline
\end{tabular}

${ }^{1}$ Endoscopy $=$ sigmoidoscopy in past 5 years or colonoscopy in past 10 years with or without FOBT; FOBT=only fecal occult blood test in the past year $*=p<0.05 ; * * p<0.01 ; * * * p<0.001$ for comparison of screening test referred to in column heading to no screening 
Table 3. Multivariate Logistic Regressions of Correlates of CRC Screening among Latinos in Three California Practice Settings, 2008-2009 $(\mathbf{N}=504)$

\begin{tabular}{|c|c|c|c|}
\hline & $\begin{array}{l}\text { Any CRC test vs. No Screening } \\
\text { Adjusted Odds Ratio }{ }^{1} \\
(95 \% \mathrm{CI})\end{array}$ & $\begin{array}{l}\text { Endoscopy vs. No Screening } \\
\text { Adjusted Odds Ratio }{ }^{1}(95 \% \text { CI) }\end{array}$ & $\begin{array}{l}\text { FOBT vs. No Screening } \\
\text { Adjusted Odds Ratio }{ }^{1} \\
(95 \% \mathrm{CI})\end{array}$ \\
\hline \multicolumn{4}{|l|}{ Physician counseling } \\
\hline Explanations of CRC risks/test ( $0-5$ scale) & $1.20(0.98,1.46)$ & $1.27(1.03,1.58)$ & $1.09(0.81,1.47)$ \\
\hline Elicitation of CRC barriers $(0-5$ scale $)$ & $0.86(0.58,1.28)$ & $0.99(0.66,1.49)$ & $0.68(0.37,1.25)$ \\
\hline Responsiveness to CRC concerns ( $0-2$ scale $)$ & $1.56(0.86,2.81)$ & $1.50(0.81,2.78)$ & $0.87(0.37,2.04)$ \\
\hline $\begin{array}{l}\text { MD encourages CRC testing (quite a } \\
\text { bit/a lot vs. a little/not at all) }\end{array}$ & $6.45(3.62,11.48)$ & $6.74(3.57,12.72)$ & $6.54(2.76,15.48)$ \\
\hline \multicolumn{4}{|l|}{ Covariates } \\
\hline \multicolumn{4}{|l|}{ Site } \\
\hline So. CA multi-specialty clinic & 1.0 & 1.0 & 1.0 \\
\hline So. CA community clinic & $0.83(0.32,2.15)$ & $0.34(0.12,0.96)$ & $4.51(0.92,22.19)$ \\
\hline No. CA community clinic & $0.42(0.18,0.98)$ & $0.21(0.08,0.55)$ & $1.52(0.34,6.93)$ \\
\hline $\begin{array}{l}\text { Colorectal cancer risk factors } \\
\text { present (vs. absent) }\end{array}$ & $2.42(1.31,4.48)$ & $3.51(1.82,6.79)$ & $0.52(0.15,1.84)$ \\
\hline
\end{tabular}

${ }^{I}$ Adjusted for other variables in the model, including education, language concordance, marital status, health insurance, and self-rated health, which were not significantly related to screening outcomes

\section{DISCUSSION}

This study examined CRC screening rates and their associations with four patient-reported measures of physician counseling about $\mathrm{CRC}$ experienced during primary care visits in a low socioeconomic status (SES) immigrant sample of Latinos in California. Our main finding was that strength of physician encouragement was the single most important communication factor associated with CRC screening. This factor overwhelmed access barriers such as LEP status, language discordant clinicians, and lack of health insurance. Furthermore, other communication factors used to increase screening, such as eliciting barriers, communicating risks and responsiveness to patient concerns, were trumped by physicians encouraging patients to obtain CRC testing. Nonetheless, shared decision-making to identify the method most congruent with patients' preferences is desirable when various CRC screening options are available and suitable.

Our findings that $59 \%$ of the sample had received CRC screening are commensurate with statewide rates for Latinos in California ${ }^{3,16}$; however, they remain inadequate. According to 2008 , National Health Interview Survey results, $52 \%$ of U.S. adults aged 50 to 75 years received CRC screening based on the most recent guidelines. ${ }^{17}$ The U.S. Department of Health and Human Services' Healthy People 2020 objective is to increase the proportion of adults who receive CRC screening from $52 \%$ to $70.5 \% .{ }^{17}$ For our study, screening results were substantially below this target despite ample opportunity to be screened; patients had on average seven medical visits in the prior year. Nationally and in California, Latinos continue to be more likely than Whites to be diagnosed with late stage CRC, ${ }^{1,16}$ highlighting the importance of increasing $\mathrm{CRC}$ screening in this population.

Results differed between endoscopy and FOBT. For endoscopic CRC screening, although physician encouragement of screening was equally important as for FOBT, providing explanations of the test was also important. For FOBT, providing explanations, eliciting patients' concerns about CRC screening and being responsive to concerns had little effect. Perhaps patients who may have had FOBT screening on prior occasions no longer viewed explanations as salient to their decision to be screened. FOBT screening rates in this sample were slightly higher $(13 \%)$ than for national data from the same period for Whites $(10 \%)$ and Latinos $(7.8 \%),{ }^{3}$ but lower compared to statewide data for California (which asks about screening in past 5 years rather than past year). ${ }^{16}$ Endoscopy rates in our sample (46\%) were lower compared to Whites nationally and statewide $(50 \%),{ }^{3,16}$ but higher than for Latinos nationally (34.6) and statewide (37\%).,16

A prior study with Latinos found that patients who discussed colon cancer risk factors with their physicians were more likely to be screened with colonoscopy. ${ }^{18}$ Our results were consistent with this finding, as both having CRC risk factors and having physicians explain the risk of cancer were associated with a higher likelihood of colonoscopy. However, a study among ethnically diverse women only (including Latinas) did not find an association between perceived risk and CRC screening. ${ }^{19}$ In another study, encouraging family members or friends to get screened was associated with a greater likelihood of colonoscopy screening among Latinos. ${ }^{18}$ These findings suggest that physicians can capitalize on traditional Latino cultural values of familism and encourage Latino patients to share information on colon cancer risks and CRC screening. This might be a promising strategy to address ethnic disparities in CRC screening.

As expected, our study found higher rates of endoscopy in the multi-specialty group than in community clinics. Promoting greater use of FOBT as the initial screening test may facilitate CRC screening in this population, and Latinos may even prefer FOBT to endoscopy initially. ${ }^{20}$ An analysis of national data found that adjusting for individual-level SES accounted for Black-White disparities in CRC screening, but not Latino-White disparities. However, adding the supply of 
primary care physicians and gastroenterologists to models accounted for Latino-White disparities in CRC screening rates (both FOBT and colonoscopy). ${ }^{21}$ Certainly, providing more resources to under-resourced community clinics, which tend to be the medical homes for the majority of Latinos, may significantly increase access and reduce disparities in CRC screening.

A strategy that might improve discussions about and physicians' recommendations for CRC screening include computerized reminder systems, ${ }^{22}$ especially among patients with more frequent primary care visits. ${ }^{23}$ A patient-focused intervention among Latino immigrants that consisted of having them watch a CRC educational video, and providing them with an informational brochure and a paper reminder for their physician, resulted in substantial increases in physician recommendations for CRC screening and screening completion. ${ }^{24}$ CRC screening rates in these primary care studies ranged from 50 to $60 \%$. To achieve Healthy People 2020 CRC screening objectives, more intensive interventions will be necessary. For example, in one study conducted among a largely low SES Latino immigrant population, FOBT screening rates of $82 \%$ were obtained utilizing multilevel, multifaceted strategies that included computerized reminders; standing orders for medical assistants to give patients home fecal immunochemical tests with low literacy instructions and postage-paid return envelopes; mailed letters and automated telephone and text message reminders for patients; and patient navigation. ${ }^{25}$

In our sample, language concordance between physicians and Latino patients was not independently associated with being screened, which is consistent with another study of CRC screening among Latinos in Northern California. ${ }^{26}$ Physicians' strong encouragement of screening may transcend language barriers.

Our study had several strengths. We examined several patient-reported physician counseling measures related to CRC screening among low SES Latinos from different California regions and varied systems of care (multi-specialty group practices and community clinics). However, results may not generalize to Latinos in other U.S. states or national origin groups other than Mexican/Central American, or beyond Latina immigrants who attend medical care regularly. Additionally, $20 \%$ of the study sample had some CRC risk factor that was suggestive of higher than average risk, which may further limit the generalizability of our findings. Screening was assessed by self-report and may overestimate actual adherence rates, although concordance of self-report with administrative and medical records CRC screening data is fairly good and ranges from about 70 to $90 \%{ }^{27,28}$ Since this study was completed, the use of a single card fecal immunohistochemical test, especially when offered with other preventive services (e.g., annual flu vaccines), has increased rates of FOBT screening. ${ }^{29}$

Our findings indicate that when a physician strongly encourages a Latino patient to undergo CRC screening, that patient is much more likely to follow through with testing. Our study revealed the strong link between patients' perceptions of the level of encouragement received for being screened and the provision of explanations about CRC testing with completion of CRC screening. Others have documented the gap between patients' desires for information on the purpose and process of CRC screening and physicians' infrequent provision of that information. ${ }^{30}$ These findings highlight the need for physicians to enthusiastically endorse evidence-based screening tests to create an encouraging environment for screening along with information on testing, and suggest where to focus attention during limited duration primary care visits. Such a focus may be especially valuable in physicianpatient interactions where significant language or cultural barriers might limit efficient use of time during medical encounters.

\section{Acknowledgements:}

Contributors: We are indebted to the staff and patients at Marin Community Clinics, St. Jude Heritage Medical Center, and St. Jude Neighborhood Health Center who made this study possible.

Funders: This work was supported by the National Cancer Institute grant numbers R21 CA121176 and U54 CA153511 (Redes En Acción) and the Resource Centers for Minority Aging Research program of the National Institute on Aging grant number P3O AG15272.

Conflict of Interest: The authors declare that they do not have a conflict of interest.

Corresponding Author: Anna M. Nápoles, PhD; Division of General Internal Medicine, Department of Medicine, and Medical Effectiveness Research Center for Diverse PopulationsUniversity of California San Francisco (UCSF), 3333 California Street, Suite 335, San Francisco, CA 94118-0856, USA (e-mail: anapoles@ucsf.edu).

\section{REFERENCES}

1. American Cancer Society. Cancer Facts \& Figures for Hispanics/Latinos 2012-2014. Atlanta, GA: American Cancer Society; 2012.

2. Chien C, Morimoto LM, Tom J, Li CI. Differences in colorectal carcinoma stage and survival by race and ethnicity. Cancer. 2005; 104:629-39.

3. American Cancer Society. Colorectal Cancer Facts \& Figures 2011-2013. Atlanta, GA: American Cancer Society; 2011.

4. Etzioni DA, Ponce NA, Babey SH, et al. A population-based study of colorectal cancer test use: results from the 2001 California Health Interview Survey. Cancer. 2004;101:2523-32.

5. Ogedegbe G, Cassells AN, Robinson CM, et al. Perceptions of barriers and facilitators of cancer early detection among low-income minority women in community health centers. J Natl Med Assoc. 2005;97:162-70.

6. Fernandez ME, Wippold $\mathbf{R}$, Torres-Vigil I, et al. Colorectal cancer screening among Latinos from U.S. cities along the Texas-Mexico border. Cancer Causes Control. 2008; 19:195-206.

7. Green AR, Peters-Lewis A, Percac-Lima S, et al. Barriers to screening colonoscopy for low-income Latino and white patients in an urban community health center. J Gen Intern Med. 2008;23:834-40.

8. O'Malley AS, Renteria-Weitzman R, Huerta EE, Mandelblatt J. Patient and provider priorities for cancer prevention and control: a qualitative study in Mid-Atlantic Latinos. Ethn Dis. 2002;12:383-91.

9. Walsh JM, Kaplan CP, Nguyen B, Gildengorin G, McPhee SJ, PerezStable EJ. Barriers to colorectal cancer screening in Latino and Vietnamese Americans. Compared with non-Latino white Americans. J Gen Intern Med. 2004; 19:156-66.

10. Geiger TM, Miedema BW, Geana MV, Thaler K, Rangnekar NJ, Cameron GT. Improving rates for screening colonoscopy: analysis of the health 
information national trends survey (HINTS I) data. Surg Endosc. 2008;22:527-33.

11. Johnson-Kozlow M, Roussos S, Rovniak L, Hovell M. Colorectal cancer test use among Californians of Mexican origin: influence of language barriers. Ethn Dis. 2009; 19:315-22.

12. Diaz JA, Roberts MB, Goldman RE, Weitzen S, Eaton CB. Effect of language on colorectal cancer screening among Latinos and non-Latinos. Cancer Epidemiol Biomarkers Prev. 2008;17:2169-73.

13. Stewart AL, Napoles-Springer AM, Gregorich SE, Santoyo-Olsson J. Interpersonal processes of care survey: patient-reported measures for diverse groups. Health Serv Res. 2007;42:1235-56.

14. Hays R, Hayashi T. Beyond Internal Consistency Reliability: rationale and User's Guide for Multitrait Analysis Program on the Microcomputer. Santa Monica, CA: RAND; 1990.

15. American Cancer Society. Detailed Guide: Colon and Rectum Cancer Available at: http://www.cancer.org/Cancer/ColonandRectumCancer/ DetailedGuide/index. Accessed November 2014.

16. Bates JH, Kwong SL, Hofer BM, Wellman JP, Snipes KP. Colorectal Cancer among Californians, 1988-2007. Sacramento, CA: California Department of Public Health, Cancer Surveillance Section; 2010.

17. U.S. Department of Health and Human Services. Healthy People 2020 Topics \& Objectives. Available at: http://www.healthypeople.gov/2020/ topicsobjectives2020/objectiveslist.aspx?topicId=5. Accessed March 16, 2014.

18. Otiniano ME, Wood RC, Poursani RS, Katerndahl DA, Siddiqui S, Nadeau MT. Association of knowledge, attitudes, and behaviors for colon cancer screening in Hispanic patients. Ethn Dis. 2013;23:343-8.

19. Walsh JM, Kim SE, Sawaya G, et al. Colorectal cancer screening: what do women from diverse ethnic groups want? J Gen Intern Med. 2013;28:23946.

20. Inadomi JM, Vijan $\mathbf{S}$, Janz $\mathbf{N K}$, et al. Adherence to colorectal cancer screening: a randomized clinical trial of competing strategies. Arch Intern Med. 2012;172:575-82.
21. Soneji S, Armstrong K, Asch DA. Socioeconomic and physician supply determinants of racial disparities in colorectal cancer screening. $\mathrm{J}$ Oncol Pract. 2012;8:e125-34.

22. Nease DE Jr, Ruffin MT, Klinkman MS, Jimbo M, Braun TM, Underwood JM. Impact of a generalizable reminder system on colorectal cancer screening in diverse primary care practices: a report from the prompting and reminding at encounters for prevention project. Med Care. 2008;46:S68-73.

23. Sequist TD, Zaslavsky AM, Marshall R, Fletcher RH, Ayanian JZ. Patient and physician reminders to promote colorectal cancer screening: a randomized controlled trial. Arch Intern Med. 2009; 169:364-71.

24. Aragones A, Schwartz MD, Shah NR, Gany FM. A randomized controlled trial of a multilevel intervention to increase colorectal cancer screening among Latino immigrants in a primary care facility. J Gen Intern Med. 2010;25:564-7.

25. Baker DW, Brown T, Buchanan DR, et al. Comparative effectiveness of a multifaceted intervention to improve adherence to annual colorectal cancer screening in community health centers: a randomized clinical trial. JAMA Intern Med. 2014; 174:1235-41.

26. Walsh JM, Salazar R, Kaplan C, Nguyen L, Hwang J, Pasick RJ. Healthy colon, healthy life (colon sano, vida sana): colorectal cancer screening among Latinos in Santa Clara. Calif J Cancer Educ. 2010;25:36-42.

27. Messina CR, Lane DS, Colson RC. Colorectal cancer screening among users of county health centers and users of private physician practices. Public Health Rep. 2009; 124:568-78.

28. White A, Vernon SW, Eberth JM, et al. Correlates of self-reported colorectal cancer screening accuracy in a multi-specialty medical group practice. Open J Epidemiol. 2013;3:20-4.

29. Potter MB, Walsh JM, Yu TM, Gildengorin G, Green LW, McPhee SJ. The effectiveness of the FLU-FOBT program in primary care a randomized trial. Am J Prev Med. 2011;41:9-16.

30. Flocke SA, Stange KC, Cooper GS, et al. Patient-rated importance and receipt of information for colorectal cancer screening. Cancer Epidemiol Biomarkers Prev. 2011;20:2168-73. 